\title{
DA CRIAÇão À FASE de Estruturação do IPEA: 1964 A 1970
}

\author{
The Creation And Structuring of the IPEA: 1964 To 1970
}

\author{
Walmir Barbosa* \\ walmir.barbosa@ifg.edu.br
}

RESUMO: A criação e a estruturação do IPEA (1964-1970) integrou um amplo processo de criação de instituições do aparato de Estado no Brasil. Envolveram elites econômicas e políticas, intelectuais orgânicos do mundo do capital (nativos e estrangeiros) e instituições nacionais e internacionais. Foi parte integrante do processo de implementação do modelo econômico desenvolvimentista, que materializava o padrão fordista-keynesiano de reprodução do capital ao mesmo tempo em que explorava as possibilidades que esse padrão e a hegemonia norte-americana permitiam. Refletiu demandas e conviç̧ões políticas e ideológicas tecnocráticas, sob o regime cívico-militar, que convergia planejamento e desenvolvimento, de um lado, e formação de instituições e quadros técnicos, de outro, que operassem, respectivamente, dentro de uma racionalidade política e administrativa e de uma competência técnico-científica e técnico-política.

PALAVRAS-CHAVE: IPEA; Estado; Intelectuais; Planejamento e desenvolvimento.

ABSTRACT: The creation and structuring of the IPEA (1964-1970) was part of a broad process of creating apparatus institutions of State in Brazil. Involved economic, political and intellectuals organic elites, of the capital's world (native and foreign) and national and international institutions. It was part of the implementation of developmental economic model process, which was materialized in the Fordist - Keynesian pattern of reproduction of capital and at the same time exploring the possibilities that this standard and the US hegemony allowed. Reflected demands, political and ideological technocratic convictions, about the civic-military regime, which converged planning and development on one hand, and training institutions and technical staff on the other, which were operating respectively, within a political and administrative rationality and a technical-scientific and technicalpolicy competence.

KEYWORDS: IPEA, State, Intellectuals, Planning and development.

\section{Introdução}

A criação e a fase de estruturação do atual Instituto de Pesquisa Econômica Aplicada (IPEA) encontraram-se inseridas em um contexto histórico marcado pelo padrão fordistakeynesiano de reprodução do capital, que internamente ao país materializava-se no modelo econômico desenvolvimentista. Modelo este que, desde o advento do Plano de Metas, apoiava-se no estabelecimento de um vínculo entre as forças materiais compostas por

\footnotetext{
* Doutor em História. Professor do curso de História do Instituto Federal de Goiás (IFG) e Pesquisador do Núcleo de Pesquisa Marxista (NUPEMARX).
} 
capitais oligopolistas e bancário-financeiros internacionais e por capitais monopolistas privados e públicos nacionais, e a superestrutura política ordenada sob relações progressivamente autoritárias, cujos desdobramentos político-sociais redundariam no golpe cívico-militar de 1964 e no processo de institucionalização do regime cívico-militar. Vínculo este que configurou modificações no bloco histórico e, consequentemente, na definição do papel que o Estado desempenharia na sociedade brasileira.

Portanto, em minha perspectiva, a investigação de temas como a estrutura administrativa do Estado, os organogramas federais nela configurados, a identificação dos centros e processos de decisões socioeconômicas, a distribuição das funções e dos recursos políticos de governos e a criação de instituições (a exemplo do IPEA), devem ser investigados a partir do supracitado padrão e do referido vínculo.

Este artigo, que se ocupa da criação e da fase de estruturação do IPEA, no contexto da institucionalização da ditadura cívico-militar, apoiou-se, fundamentalmente, em fontes bibliográficas e em entrevistas conduzidas junto a técnicos do IPEA.

\section{A criação do IPEA}

A criação do IPEA foi o resultado de diversos processos e influências que vão desde a necessidade de um órgão técnico-científico e profissionalizado, voltado para o desenvolvimento das atividades de fomento, planejamento e coordenação econômica, às necessidades e imperativos impostos pelo modelo econômico desenvolvimentista e por seu padrão de acumulação e financiamento dependente-associado.

A ideia de criação de uma agência governamental de planejamento foi objeto de discussões e encontros envolvendo altos funcionários do governo brasileiro, como Roberto de Oliveira Campos e de Otávio Gouveia de Bulhões, bem como entre estes altos funcionários e dirigentes da Fundação Getúlio Vargas e do governo norte-americano.

Foram mantidos contatos com a United States Agency for International Development (USAID), ${ }^{1}$ que mobilizaria universidades norte-americanas para incorporar ao novo órgão de planejamento do Estado brasileiro a competência técnica que faltaria ao país. Nessa perspectiva, também foram mantidos contatos com organismos internacionais como o Fundo Monetário Internacional (FMI) e o Banco Internacional de Reconstrução e Desenvolvimento (BIRD) (CARVALHO, 1996).

\footnotetext{
${ }^{1}$ A United States Agency for International Development (USAID) é um órgão do governo dos Estados Unidos encarregado de distribuir ajuda externa de caráter civil. É um organismo independente, embora atue orientado pelas diretrizes estratégicas do Departamento de Estado dos Estados Unidos.
} 
No que tange à influência externa, o surgimento do IPEA usufruiu de uma onda institucional de amplitude mundial, a partir da qual várias agências e instituições com estas características foram criadas. Os fundamentos da referida onda institucional residem no padrão fordista-keynesiano de reprodução do capital, que se produziu e se reproduziu com base no Acordo de Bretton Woods, proporcionando uma espécie de contexto de partida (ENTREVISTADOS 2, 3 e 5). Esta onda institucional concorreu para um processo de construção institucional ampla no país, onde primeiramente foram criadas instituições como o Banco Nacional de Desenvolvimento Econômico e Social (BNDES) e a Superintendência da Moeda e do Crédito (SUMOC), sendo posteriormente criadas outras como o Banco Central, o IPEA e o Banco Nacional de Habitação (BNH).

Nesta direção, alguns entrevistados realçaram que o processo de complexificação da economia brasileira, desde a entrada do capital internacional, passou a demandar uma instituição que concorresse para planejar o desenvolvimento econômico que se articulara com base no tripé formado por capitais privados nacionais e internacionais e capital estatal ${ }^{2}$, bem como para contornar os desequilíbrios econômicos setoriais que se intensificavam com a referida complexificação (ENTREVISTADOS 2 e 3). Também foi realçado que a complexidade e desequilíbrios econômicos passaram a estimular determinados economistas a desenvolver modelos macroeconômicos com vista ao desenvolvimento e coordenação da economia brasileira, com destaque para um modelo desenvolvido por Mário Henrique Simonsen, bem como foi acentuada a necessidade de criação de uma instituição centrada na abordagem econômica aplicada (ENTREVISTADO 2).

As origens do IPEA também remontam ao final do Governo Goulart, quando foi criada a Associação Nacional de Programação Econômica e Social (ANPES), em 1964, com o objetivo de realizar estudos para o desenvolvimento de planos de governo. Os objetivos da ANPES coadunavam com a perspectiva de criação de modelos macroeconômicos voltados para o desenvolvimento e a coordenação econômica.

A demanda por uma instituição de pesquisa econômica aplicada, cujo itinerário fosse a concepção de "planos de governo futuros", compunha as preocupações de empresários e de liberais conservadores à época. Essas preocupações expressam uma espécie de 'espírito de época', sobretudo nas perspectivas de altos funcionários públicos, a exemplo de Roberto Campos, e de intelectuais de grande influência política, a exemplo de Mário Henrique Simonsen, que também eram intelectuais orgânicos de funções amplas vinculados ao mundo do capital, qual seja, acentuar a importância do Estado como instituição voltada para o planejamento e coordenação econômica ajustado ao atendimento das demandas articuladas

\footnotetext{
${ }^{2}$ O entrevistado 3 afirmou que a construção institucional ampla, da qual resultou o IPEA, era orientada pelo objetivo de "efetivar o desenvolvimento pela via de um capitalismo industrial consolidado, ampliando as margens de autonomia nacional, mas com a presença do capital internacional - o tripé do desenvolvimento -, no contexto da regulação de Bretton Woods".
} 
à expansão do que denomino por padrão fordista-keynesiano de reprodução do capital, em termos mundiais, e do modelo econômico desenvolvimentista, como materialização desse padrão no país. ${ }^{3}$

O surgimento do IPEA também guarda uma relação estreita com o surgimento e a trajetória histórica do Instituto Brasileiro de Economia (IBRE) da Fundação Getúlio Vargas (FGV), o primeiro instituto de pesquisa econômica aplicada do país, criado em 1951. Eugênio Gudin e Otávio Gouveia de Bulhões estiveram diretamente envolvidos com o IBRE nas suas primeiras décadas de existência, assegurando prestígio à instituição. Dentre as atividades de maior destaque nesta primeira fase, que se estendeu de 1951 a 1964, pode-se destacar o trabalho de preparação do balanço de pagamentos e as 'contas nacionais'4. Dessa forma, o IBRE concorria para o desenvolvimento de instrumentos necessários para a produção de informações e análises econômicas que os órgãos governamentais ainda não possuíam, mas que eram cruciais para a condução de fomento, planejamento e coordenação econômica.

O processo de estruturação e consolidação do IBRE envolveu o estabelecimento de vínculos estreitos com os meios acadêmicos nacionais, em especial com a Faculdade Nacional de Ciência Econômica (FNCE) da então Universidade do Brasil, e estrangeiros, a exemplo da Universidade de Vanderbilt, mas também envolveu vínculos com organismos internacionais, como a Fundação Rockfeller e o Departamento de Agricultura dos Estados Unidos. Com relação às universidades norte-americanas, o IBRE assegurou o envio sistemático de seus quadros para estágios nessas instituições. Por outro lado, segundo Maria Rita Durand, manteve-se "recebendo pesquisadores visitantes dos Estados Unidos e Europa, como G. Harlerler, N. Kaldor, G. Myrdal, R. Nurkse, Raul Prebisch e J. Viner" (DURAND, 1997, p. 105). Esses processos permitiram ainda que a instituição assumisse um "caráter marcadamente acadêmico e cosmopolita, definindo-se como centro divulgador das informações científicas e técnicas trazidas de outros países" (DURAND, 1997, p. 105). Portanto, o IBRE constituiu-se em uma referência fundamental para a criação e a fase de estruturação do IPEA (EPEA).

\footnotetext{
${ }^{3}$ Nas palavras de Mário Henrique Simonsen: "Antes do IPEA havia uma associação privada chamada ANPES (Associação Nacional de Programação Econômica e Social), financiada por vários empresários, sobretudo de São Paulo, cujo presidente era Roberto Campos, cujo diretor técnico era eu, cujo diretor administrativo era o Vitor da Silva. Essa Associação começou antes do Governo Castello Branco (...), no final do Governo Goulart e nós começamos fazendo cursos para o desenvolvimento de planos de governo futuros, sem realmente a pretensão de que aquilo pudesse dar resultados imediatos. Bom, pouco tempo depois vem a Revolução de março de 1964, alguns dias depois Roberto Campos é nomeado ministro do Planejamento, e poucos dias depois chega com o seu mestrado de Yale João Paulo dos Reis Velloso, que se incorporou imediatamente à ANPES e aos seus grupos de estudos" (GALINKIN, 1989). A ANPES também publicou estudos econômicos aplicados que poderiam balizar "planos de governos futuros", a exemplo do trabalho intitulado 'Alguns Aspectos na Inflação Brasileira', de Antonio Delfim Netto, em 1964.

${ }^{4}$ As 'contas nacionais' compõem estatísticas necessárias à implementação das políticas macroeconômicas de inspiração keynesiana. No tocante aos índices de preços, em especial na economia estruturalmente inflacionária brasileira, estes indicadores permitiram o estabelecimento do instituto da correção monetária, por meio da Lei 4.357, de 16 de julho de 1964.
} 
Foi criado então o IPEA, tendo como seu primeiro nome Escritório de Pesquisa Econômica Aplicada (EPEA), em setembro de 1964, no âmbito do Ministério do Planejamento (BRASIL, 1964), com a "missão" de "pensar o Brasil no médio e longo prazo, fora do dia-a-dia da gestão da economia" (VELLOSO, 2007, p. 193). Esta “missão" seria orientada mediante estudos e pesquisas necessárias ao planejamento econômico.

Os objetivos que deveriam nortear a atuação do IPEA (EPEA) não estavam muito bem definidos, conforme pode-se depreender da seguinte passagem do depoimento prestado por João dos Reis Velloso, no vídeo Comemoração dos 25 anos do IPEA:

Quando eu me apresentei recebi a incumbência de criar algo que ele próprio [Roberto Campos] denominou de Escritório de Pesquisa Econômica Aplicada (EPEA), que a gente não sabia direito o quê que iria ser. Apenas se tinha a ideia do enfoque, ou seja, seria algo que ajudasse o ministro do Planejamento a pensar. Uma espécie de um brain trust, um think thank para o ministro do Planejamento. (GALINKIN, 1989)

Nesta passagem, João Paulo dos Reis Velloso, em sintonia com Roberto Campos, compreendia que o IPEA (EPEA) deveria ser uma espécie de organização institucional de assessoria do Ministério de Planejamento, concebido para atender elevados padrões de racionalidade e de aplicabilidade de conhecimentos especializados nele demandados. Reis Velloso reafirmou esta compreensão quando disse que "o IPEA foi criado para institucionalmente assessorar o governo. (...) O planejamento em certo sentido deve ser também o órgão de assessoramento" (GALINKIN, 1989). A nova instituição deveria se voltar para a pesquisa aplicada direcionada para a formulação de políticas (policy) no âmbito desse ministério.

Segundo Reis Velloso, embora não soubesse direito o que deveria ser o IPEA (EPEA), "nós sabíamos apenas que ele não podia ser uma repetição da Fundação Getúlio Vargas. Quer dizer, ele não ia fazer estudos acadêmicos, seria algo aplicado, daí o nome do Escritório, e voltado realmente para a formulação de policy" (GALINKIN 1989). Essa perspectiva convergiu na direção de conceber o IPEA (EPEA) como instituto de pesquisa aplicada de caráter econômico. ${ }^{5}$

A instituição, enfim, foi concebida por Roberto Campos e Reis Velloso, para os quais ela deveria se constituir em um órgão pensante, de caráter plural, desvinculado diretamente

\footnotetext{
${ }^{5}$ Segundo Durand (1997, p. 109): “Aos poucos, a ideia de constituição de um "think thank", isto é, de um órgão pensante dentro do próprio governo, no qual se formularia, através de estudos sistemáticos e debates constantes dos problemas nacionais, a visão estratégica para o País, foi tomando forma e se consolidou com a própria transformação do Epea em Ipea, em 1967, no bojo do Decreto 200 da reforma administrativa. Segundo ainda palavras do próprio Reis Velloso, com o Ipea institucionalizou-se o planejamento governamental no Brasil, mas este era visto menos como uma metodologia e mais como um núcleo provedor de ideias para a sociedade".
} 
das rotinas de governo e que se ocupasse do planejamento de médio e de longo prazo. ${ }^{6}$ Para que o IPEA (EPEA) se transformasse em um "órgão pensante de governo" deveria ser orientado por meio de cinco grandes princípios: criatividade, pluralidade, mérito, protagonismo e relevância. ${ }^{7}$

As preocupações com "a criação e consolidação institucional da administração pública brasileira" refletiam a importância que o Estado e o planejamento estratégico assumiam no modelo econômico desenvolvimentista e no padrão de acumulação e financiamento dependente-associado, tanto por parte das diversas vertentes políticas e ideológicas das elites políticas tradicionais e político-administrativa brasileiras, como também por parte da elite político-administrativa vinculadas às instituições internacionais. A perspectiva de conquista da 'relevância institucional' por parte do IPEA (EPEA) era parte integrante dessas preocupações.

As iniciativas voltadas para "a criação e consolidação institucional da administração pública brasileira" eram permeadas por disputas de espaço e poder institucional em torno de aspectos como as orientações econômicas do Governo Federal e o sentido da construção da arquitetura institucional do Estado. Deve-se ter claro que as disputas entre as elites políticas tradicionais e político-administrativa, transcorridas dos anos 1940 aos anos 1960, contrapondo elites identificadas com projetos de desenvolvimento com 'acento' nacionalista e com 'acento' internacionalista, foi parte integrante das contradições e conflitos que culminaram no golpe cívico-militar de 1964 e no regime que o sucedeu. Como consequência, ocorreu uma repressão às elites políticas tradicionais e político-administrativa identificadas com projetos políticos com 'acento' nacionalista e o afastamento das mesmas das instâncias decisórias e de órgãos e agências do Estado.

O processo de institucionalização do regime cívico-militar acentuava o Estado como lócus privilegiado das lutas e disputas políticas, sobretudo por parte das forças políticas

\footnotetext{
${ }^{6}$ Nas palavras de João Paulo dos Reis Velloso, secretário-geral do Ministério do Planejamento entre 1964 e 1968 (que nessa condição presidia o IPEA) e ministro desse ministério entre 1969 e 1979, "Pretendíamos que o IPEA fizesse pesquisa econômica aplicada, ou seja, policy-oriented, e que ajudasse o governo a formular o planejamento, em uma visão estratégica de médio e longo prazos". (D'ARAUJO, DE FARIAS e HIPPOLITO, 2005, p. 21)

${ }^{7}$ Segundo Reis Velloso: “O primeiro, ter uma visão criativa e global, pensar com inovação, ser uma consciência crítica do governo. $O$ segundo foi o da pluralidade: acolher pessoas que tivessem talento, independentemente de suas preferências ideológicas. O terceiro era construir uma carreira própria, que enfatizasse o mérito e valorizasse a excelência técnica, mas sempre com transparência. Mandávamos nossos técnicos para fazer doutorado no exterior, investíamos neles e queríamos valorizá-los. (...) O quarto, ser um institution builder. Nós nos preocupávamos com a criação e a consolidação institucional da administração brasileira - o IPEA criou ou ajudou a criar vários órgãos. (...) Finalmente, o princípio da relevância: se fosse relevante para o governo, o IPEA seria importante. Por isso, estávamos sempre presentes nas questões-chave, fossem do crescimento, fossem da área social". (D'ARAUJO, DE FARIAS e HIPPOLITO, 2005, p. 28)
} 
vitoriosas diretamente vinculadas ao Estado, isto é, entre as elites políticas tradicionais e a elite político-administrativa e, no âmbito desta, a luta pela afirmação da fração dos economistas técnicos em face das demais frações. Deve-se considerar, ainda, que embora determinadas instituições fossem instrumentalizadas nesta luta, a própria instituição compunha uma força institucional que se somava aos projetos dos seus técnicos individualmente e do seu quadro técnico como um todo. Portanto, mesmo instituições e órgãos da tecnoestrutura da área econômica do aparato de Estado, com grande presença de economistas técnicos, estavam permeadas por disputas por espaço e poder institucional em relação a outras instituições que compunham a referida tecnoestrutura.

Finalmente, na criação do IPEA (EPEA) era estabelecida, como sua função primordial, o desenvolvimento do planejamento estratégico de Estado ${ }^{8}$. Portanto, esse planejamento, que deveria nortear a atuação da instituição, teria que proporcionar as condições para impulsionar as forças criativas da "sociedade" - um eufemismo dado à iniciativa privada. Assim, o Estado e o seu planejamento estratégico, para o qual a instituição se empenharia, deveriam assegurar uma política econômica racionalizada que impulsionasse a acumulação e o crescimento econômico da iniciativa privada, na direção do desenvolvimento econômico. ${ }^{9}$

\section{IPEA, planejamento e desenvolvimentismo conservador nos anos 1960}

O IPEA e a questão do planejamento, quando situadas em relação ao núcleo de ações e iniciativas estratégicas do regime cívico-militar, orientado para o que este regime compreendia como 'desenvolvimento', proporcionam novos elementos para a compreensão e a análise da criação e da estruturação do IPEA, entre 1964 e 1970. A obra 'Brasil 2001', de Mário Henrique Simonsen, é paradigmática nesse sentido, posto que pode ser considerada

\footnotetext{
${ }^{8}$ Segundo Reis Velloso: "Como o planejamento tem que ter essa visão estratégica do país, e visão estratégica que inclui ver o desenvolvimento como a transformação da sociedade, inclusive do ponto de vista político, eu acho que essa ordem de cogitações transcende meramente o Executivo. (...) Quem tem as ideias em geral ganha as paradas políticas. Então é preciso que o planejamento esteja na vanguarda das ideias para o desenvolvimento do Brasil" (GALINKIN, 1989). Ainda nas palavras de João Paulo dos Reis Velloso: "Planejamento, segundo entendo, dentro da concepção de James Tobin, prêmio Nobel de economia, para quem o planejamento era a racionalização da política econômica - ou política de desenvolvimento, no nosso caso. E de Salvador de Madariaga, o grande liberal espanhol, que atribuía ao planejamento a função de liberar as forças criativas das sociedades". (D'ARAUJO, DE FARIAS e HIPPOLITO, 2005, p. 40)

${ }^{9} \mathrm{Em}$ outra passagem, João Paulo dos Reis Velloso realçou que a concepção de planejamento que orientou o surgimento e a trajetória do IPEA cumpria uma espécie de etapa necessária para que países não desenvolvidos alcançassem o desenvolvimento: "Trata-se (...) de uma visão estratégica para a economia de mercado, necessária em países como o Brasil, ainda não plenamente desenvolvidos. E, portanto, cheios de falhas de mercado, de mercados imperfeitos (com assimetria de informações, principalmente) e falhas de governo. Países, por isso mesmo, em que os "substitutos históricos" (à la Gerschenkron) ainda são importantes - o Estado (na definição de estratégias), os bancos de desenvolvimento, e até mesmo a ideologia do desenvolvimento (melhor: a idéia de desenvolvimento como valor social)". (VELLOSO, 2007, p. 193 e 194)
} 
uma expressão do desenvolvimentismo conservador que informou o crescimento econômico no referido regime.

Simonsen (1969, p. 269-284), ao discorrer sobre diversos modelos (ou estratégias) de 'desenvolvimento' - Estados Unidos, União Soviética, Japão, Alemanha e Israel -, procurou identificar o núcleo de ações estratégicas voltados para o 'desenvolvimento' em cada país estudado. A perspectiva presente na obra era identificar o núcleo de ações estratégicas comuns aos países (quais sejam: poupança, educação e racionalidade econômica e administrativa) e, à luz do estágio do 'desenvolvimento' alcançado pelo Brasil, propor um conjunto de iniciativas estratégicas que as implementasse, tendo em vista dar consecução ao 'desenvolvimento' brasileiro em uma qualidade superior, isto é, imprimir qualidade ao processo de modernização e de industrialização cuja expansão, no seu entendimento, tinha sido basicamente quantitativa. ${ }^{10}$

Subliminarmente a este núcleo de ações estratégicas comuns aos países estão presentes aspectos como a submissão da política à economia, a identidade entre desenvolvimento e crescimento econômico e a subordinação das políticas sociais às supostas conquistas econômicas. Aspectos que marcaram a trajetória do Estado Brasileiro, que se estendeu inclusive ao próprio IPEA. ${ }^{11}$

A materialização do núcleo de ações estratégicas no país, em prol da política de desenvolvimento proposta por Mário Henrique Simonsen, consistia no cumprimento de uma espécie de 'regras de passagem' que permitiria a superação de "cinco grandes problemas": 1. Aumentar a poupança interna; 2 . Elevar os níveis de educação e de domínio tecnológico; 3

\footnotetext{
${ }^{10}$ Simonsen chegou à seguinte conclusão: "Os cinco exemplos citados, o dos Estados Unidos, o da Alemanha, o da União Soviética, o do Japão e o de Israel desenvolveram-se em contextos inteiramente diferentes em matéria de dotação de recursos naturais, de estrutura política, de ordem jurídica, e de tradições culturais. Todos eles, no entanto, basearam-se no tripé "poupança-educação-racionalidade econômica e administrativa". (...) Todo processo de desenvolvimento resulta de uma opção a favor do futuro e contra o presente. Isso torna inviável a tão saborosa ideia do desenvolvimento sem sacrifícios. (...) Para dar um exemplo, um país que deseje expandirse aceleradamente, não pode cometer prodigalidades em matéria de política salarial, sob pena de ter mutilada a sua capacidade de poupança. (...) Essas observações nos devem pôr em guarda contra aquele tipo de reformismo histérico, muito do gosto de esquerdistas e estruturalistas, segundo o qual o principal obstáculo ao nosso desenvolvimento está nas resistências contra a implantação das reformas de base. É óbvio que o desenvolvimento exige mobilidade social e um conjunto adequado de instituições (muitas delas, aliás, já vêm sendo reformadas desde 1964), mas o tipo de pregação em causa encerra três defeitos básicos: primeiro, o de salientar os aspectos mais fáceis, e omitir os mais árduos da política de desenvolvimento; segundo, o de envolver as reformas em critérios ideológicos, ao invés de orientá-las numa direção pragmática; terceiro, o de recomendar um distributivismo prematuro nocivo ao potencial de poupança e à eficiência do trabalho. Os exemplos citados mostram que o desenvolvimento acelerado é compatível com várias alternativas institucionais. Mas nenhum quadro institucional leva ao desenvolvimento se não estiver apoiado no tripé poupança - educação - racionalidade econômica. (SIMONSEN, 1969, p. 280-284)

${ }^{11}$ Isto fica evidenciado na autocrítica que Roberto Cavalcanti de Albuquerque, técnico do IPEA, realizou acerca da atuação dessa instituição nos anos 1960 e 1970, quando disse: “(...) naquela época a questão social ainda era colocada num segundo plano. E este é um dos equívocos de que a gente tem que se penitenciar" (GALINKIN, 1989).
} 
conter a explosão demográfica; 4. Expandir as exportações; e 5. Formar uma elite técnica qualificada (SIMONSEN, 1969, p. 284).

O conjunto de iniciativas estratégicas indicado por Simonsen, voltado para o 'desenvolvimento', tinha como objetivo criar as condições para a continuidade do 'crescimento econômico' sobre outras bases. ${ }^{12}$ Daí a preocupação com aspectos como o equilíbrio entre os protagonismos do Estado como agente econômico direto e da iniciativa privada, a ação estatal prioritariamente voltada para promover as condições institucionais impulsionadoras da produção e reprodução do capital na esfera privada, a ampliação da exportação de produtos primários, a elevação da produtividade e da competitividade da estrutura produtiva industrial mediante a redução do coeficiente de nacionalidade nela contidos e a condução de políticas de contenção da "explosão demográfica"13.

Na perspectiva desse artigo cabe destacar a preocupação de Simonsen com questões como planejamento, elite técnica e cultura racional-pragmática. Simonsen atribuiu à falta de uma elite técnica racional e pragmática, familiarizada com o planejamento e a programação

\footnotetext{
12 Os chamados "cinco grandes problemas" e as ações voltadas para a superação dos mesmos consistiam em, primeiro lugar, aumentar a poupança interna por meio da compressão das despesas do governo, do prestígio ao lucro do setor privado e incentivo à sua reinversão, do estímulo aos indivíduos para economizar através da criação de instrumentos atrativos no mercado de capitais e da atração aos capitais estrangeiros. Em segundo lugar, elevar os níveis de educação de modo a erradicar o analfabetismo, generalizar o ensino básico, transformar o segundo grau num valor terminal com a multiplicação dos currículos técnicos, estimular os cursos superiores técnicos de carreiras curtas, desestimular a proliferação das universidades-prestígio, e estimular a incorporação de tecnologia no processo produtivo através da formação de recursos humanos e da condução de política econômica orientada nessa direção. Em terceiro lugar, enfrentar a explosão demográfica inicialmente por meio do reconhecimento oficial do problema e da criação de postos de assistência e instrução sobre a matéria, e da superação da condição semiclandestina dos anticoncepcionais. Em quarto, realizar a expansão das exportações apoiada na manutenção de política cambial realista, na ampliação de incentivos fiscais à exportação, na melhoria dos serviços portuários, na desburocratização dos canais de comércio, na adoção de política comercial externa agressiva, na superação do preconceito de que é indesejável exportar produtos primários, na retificação da estrutura industrial para adequá-la aos índices de produtividade e de competitividade internacionais e na superação da obsessão pelos elevados índices de nacionalização dos bens de capital e dos produtos gerados. Por fim, em quinto lugar e último grande problema e ações voltadas para a superação do mesmo, realçou criar uma educação de elites com vistas à formação de quadros que pudessem conduzir o país à racionalidade econômica e administrativa indispensável ao desenvolvimento e que estes fossem capazes de criar horizontes de programação de longo prazo e cultura pragmática, de atender a demanda por formação de quadros administrativos necessários para a execução de programas de desenvolvimento e de superar o apego à inflação desenvolvimentista (SIMONSEN, 1969, p. 284-291). Ao discorrer sobre os cinco grandes problemas do desenvolvimento brasileiro, o autor resumiu, a meu ver, o que foi uma espécie de programa informal de atuação do Estado, dos governos cívico-militares e, consequentemente, do próprio IPEA, em uma perspectiva de desenvolvimentismo conservador.

${ }^{13}$ A questão demográfica foi abordada dentro de uma perspectiva neomalthusiana, embora de modo subliminar. Segundo Simonsen, "o que nos deve preocupar não é a possibilidade de expandir o produto real a taxas superiores à da expansão populacional, o que parece bastante viável, mas a recuperação do atraso de nossa renda per capita em relação à das taxas de aumento demográfico. Como ninguém cogitará de fechar o país aos progressos da medicina moderna, a solução está em conter as taxas de natalidade. É possível que se trate de um problema difícil, mas essa não é uma razão para que fiquemos de braços cruzados aderindo ao fatalismo demográfico" (SIMONSEN, 1969, p. 288).
} 
econômica, nas esferas pública e privada, uma das causas da perda de oportunidades de crescimento econômico e do "atraso" do país. A sua grande preocupação, no que tange aos aparatos administrativos do Estado e das empresas privadas, era disponibilizar aos mesmos uma elite profissional capacitada na condução de iniciativas voltadas para o desenvolvimento dentro de uma racionalidade econômica nos termos acima identificados e de conformar progressivamente uma "tradição" de pensar em médio e longo prazo. Para além do fato de ignorar aspectos como a herança colonial, a constituição de uma economia mundial que estabelece países centrais e países periféricos e a deterioração dos termos de troca, bastante em voga nos anos 1960 graças às abordagens estruturalistas e marxistas, ele acentuou a questão do desenvolvimento como eminentemente endógeno, de um lado, relacionado à aplicação da 'regra de passagem' representada pela superação dos chamados "cinco grandes problemas", e, de outro, relacionado diretamente às elites e instituições, respectivamente, educadas e concebidas segundo a racionalidade econômica, capazes de conduzir a política do desenvolvimento (com destaque para a política econômica) coerentemente orientada para a superação dos "cinco grandes problemas". ${ }^{14}$

O engajamento de Mário Henrique Simonsen com a formação de uma elite e de instituições dentro dos princípios de racionalidade econômica e de planejamento em médio e longo prazo, acima referido, ficou evidenciado na sua participação na criação e direcionamento da ANPES, no final do Governo Goulart, como organização da sociedade civil referenciada no mundo do capital, em grande medida antecessora do IPEA (EPEA). Também ficou expresso nos posicionamentos críticos acerca dos cursos de Economia, que, segundo Mário Henrique Simonsen, não observavam critérios de qualidade, e dos seus graduados, que não eram corretamente avaliados, o que comprometia a formação de economistas em nível elevado, integrados à elite nos termos anteriormente assinalados (SIMONSEN, 1966, p. 19).

\footnotetext{
${ }^{14}$ Segundo Simonsen era necessário a condução de “(...) uma educação de elites que conduza o país à racionalidade econômica e administrativa indispensável ao desenvolvimento. Infelizmente nem temos a tradição de pensar o longo prazo nem de raciocinar pragmaticamente nas questões econômicas. A estreiteza dos horizontes de programação nos levou à perda dos mercados externos pela valorização artificial dos produtos, ao excessivo apego à inflação desenvolvimentista e ao endividamento internacional desordenado, e a uma industrialização quantitativamente brilhante, mas em muitos casos mal dimensionada e excessivamente onerosa. A falta de pragmatismo levou-nos ao desperdício de inúmeras oportunidades de crescimento e ao caos da produção e da moeda por volta de 1963 . Ao mesmo tempo ressentimo-nos da falta dos quadros administrativos indispensáveis à boa execução de um programa de desenvolvimento. Isso é verdade no setor privado, onde seria necessário refinar os métodos de decisão dos empresários, e particularmente no setor público, que peca pela excessiva centralização, pelo inútil desperdício burocrático, pela aversão à responsabilidade, e pela mais volúvel descontinuidade das equipes dirigentes. É fora de dúvida que, desde 1964, melhoramos consideravelmente os nossos métodos de formulação da política econômica, a qualidade da administração pública e até a sofisticação dos empresários privados (que tiveram que entender a correção monetária e se preparar para o combate à inflação). Resta saber se alcançamos o equilíbrio estável. Parte de nossas elites ainda se perde em discussões economicamente irracionais e que nenhum proveito trazem ao crescimento do país. E a racionalidade deve emergir como uma atitude espontânea das elites, e não como uma imposição militar". (SIMONSEN, 1969, p. 290 e 291)
} 
O pensamento e as elites liberais conservadoras presentes no Estado, ou mesmo liberais conservadores que individualmente se envolveram na concepção e criação do IPEA, estavam absorvidos na estrutura e dinâmica político-institucional e econômica desenvolvimentista. ${ }^{15}$

Em minha perspectiva, o desenvolvimentismo foi a tônica de desenvolvimento de diversos países periféricos e centrais no âmbito do sistema capitalista mundial, na vigência do padrão fordista-keynesiano de reprodução do capital e da hegemonia norte-americana. 0 desenvolvimentismo também foi uma manifestação política e ideológica integrada à teoria do desenvolvimento dos anos 1950 e 1960, com a perspectiva de explorar as margens de crescimento econômico que os referidos padrão e hegemonia consentiam.

Pode-se reconhecer nos altos funcionários e nos intelectuais vinculados ao regime cívico-militar, a exemplo de Mário Henrique Simonsem, a condição de intelectuais orgânicos de funções amplas do capital, que deram continuidade ao processo de convergência entre as determinações da rede internacional de instituições desenvolvidas no âmbito do padrão fordista-keynesiano de reprodução do capital e os horizontes de consciência possível das classes dominantes brasileiras, dentro das possibilidades e limites que este padrão e a hegemonia norte-americana estabeleciam. Convergência esta que permitiu levar mais adiante o modelo econômico desenvolvimentista e o padrão de acumulação e financiamento que se configurou como dependente-associado desde o Plano de Metas, mediante a criação de políticas e instituições que potencializassem a exploração das referidas possibilidades e limites, a exemplo do IPEA.

\section{A estruturação e influência acadêmica do IPEA}

O IPEA apresentou uma forma de organização pouco complexa e não existia qualquer separação entre as atividades de pesquisa e de planejamento, durante a sua fase inicial de

\footnotetext{
${ }^{15}$ Maria da Conceição Tavares expressou, de certo modo, essa realidade quando disse: "Todos eram de alguma maneira desenvolvimentistas, todos tinham consciência de que a coisa tecnológica era complicada, ta lá no primeiro relatório. Que a coisa era complicada e que tinha que completar o processo da industrialização. Então, havia consenso em três pontos: a coisa tecnológica era importante, (...) a coisa da estrutura industrial tinha que completar; e a coisa social era grave e precisava ver e a coisa regional, havia a primeira crítica, os subsídios da SUDENE não tinham dado resultado. Então, a visão global do estado de desequilíbrios era muito claro no IPEA. Quer dizer, todos os técnicos se juntaram e de todas as partes do Brasil, como eu te digo, tinham claro uma visão nacional, quer dizer, era um projeto nacional. Estava-se ainda começando a elaborar um projeto nacional" (GALINKIN, 1989).
} 
estruturação. A organização interna dos grupos de estudo e pesquisa do IPEA, por sua vez, praticamente seguia a organização dos capítulos dos planos de desenvolvimento ${ }^{16}$.

O núcleo (ou setor) de planejamento geral, com a função institucional de conceber e formalizar a estratégia macroeconômica do Governo Federal, e os vários núcleos (ou grupos) setoriais, com a função institucional de conceber e formalizar as estratégias governamentais setoriais vinculadas às atividades de produção (agricultura e abastecimento, indústria) e de infraestrutura econômica e social (comércio internacional, desenvolvimento regional e urbano, educação e mão-de-obra, energia, finanças públicas, habitação, política monetária, saúde, telecomunicações, transportes, etc.), serviu aos interesses vinculados à permanência na Cidade do Rio de Janeiro e ao deslocamento para a Cidade de Brasília, materializados na criação do Instituto de Pesquisa (INPES) e do Instituto de Planejamento (IPLAN).

O INPES e o IPLAN foram criados na passagem dos anos 1960 para os anos 1970, mais precisamente em julho de 1970. O INPES foi montado no Rio de Janeiro, a partir do setor de planejamento geral, e o IPLAN em Brasília, a partir dos grupos de estudos setoriais então transferidos e/ou estruturados em Brasília. A divisão de atribuições no âmbito do IPEA, cuja materialização se configurou no INPES e no IPLAN, com consequente perfil técnico específico requerido por cada instituto, não se fez presente na concepção e na criação da Instituição.

Observa-se que o EPEA foi concebido para reunir as dimensões de planejamento, aglutinando pessoal técnico com competência em projeções proporcionados por modelos macroeconômicos, e de coordenação, com pessoal técnico de perfil executivo. Embora se possa concluir que a primeira dimensão requeresse competência técnico-acadêmica e a segunda técnico-política, elas não foram apartadas no EPEA, nem mesmo quando a entidade foi renomeada para IPEA por meio do Decreto-Lei 200 (BRASIL, 1967).

A divisão de atribuições e de perfil técnico que redundou no INPES, encarregado da pesquisa acadêmica, e no IPLAN, responsável pela assessoria e coordenação das atividades próximas do Governos federal e dos governos estaduais, não decorreu de uma reflexão que redundasse na separação das atividades de pesquisa e de planejamento (TOLOSA, 1989). Esta divisão não decorreu de uma intenção a priori, mas da resistência de um grupo de técnicos em se deslocar para Brasília (ENTREVISTADO 2). Entre aqueles mais jovens, de formação acadêmica mais sólida, predominou a permanência no Rio de Janeiro, ou retornaram posteriormente para esta cidade. Entre aqueles mais experientes, oriundos das superintendências de desenvolvimento (sobretudo, SUDENE), das secretarias de planejamento (SEPLAN) estaduais e de outros órgãos federais, predominou a permanência

\footnotetext{
${ }^{16}$ Nas palavras de Tolosa (1989, p. 6): “Havia o núcleo de Planejamento Geral, encarregado de conceber e formalizar a estratégia macroeconômica do governo, e vários setores organizados de acordo com a produção (agricultura e abastecimento, indústria) e com a infraestrutura econômica e social (comércio internacional, desenvolvimento regional e urbano, educação e mão-de-obra, energia, finanças públicas, habitação, política monetária, saúde, telecomunicações, transportes, etc.)".
} 
em Brasília. Portanto, a separação foi em grande medida determinada pelas resistências desencadeadas pelo deslocamento do IPEA para Brasília e pelas necessidades de apoio técnico-científico às atividades de planejamento e coordenação, sobretudo econômica, junto ao Governo Federal em Brasília (ENTREVISTADOS 1 e 2).

Esta divisão induziu a papéis e representações sociais distintos: o IPLAN, ocupado por técnicos graduados em Economia e em outras áreas com funções basicamente 'técnicopolíticas' de assessoramento e coordenação econômica e social ${ }^{17}$; e o INPES, ocupado basicamente por economistas técnicos com funções 'técnico-científicas' voltadas para projeções de longo prazo, com base em modelos macroeconômicos. ${ }^{18}$

A separação acarretou problemas ao INPES quanto à identificação de como fazer os estudos e pesquisas aplicadas, dirigidas, sobretudo para o planejamento. Referindo-se aos "técnicos jovens", segmento que predominou na constituição do INPES, Hamilton Tolosa constatou que não possuíam uma visão clara acerca de pesquisa direcionada ao planejamento (TOLOSA, 1989, p. 6). ${ }^{19}$

Os vínculos do INPES com a pesquisa fortemente acadêmica também ficaram demonstrados no fato de que uma parte significativa destes economistas acadêmicos e técnicos do INPES eram ou viriam a ser professores da Escola de Pós-Graduação em Economia (EPGE) da FGV e do Departamento de Economia da PUC-RJ. As referências teóricas

\footnotetext{
${ }^{17}$ Em que pese a diversidade das áreas de graduação dos técnicos do IPEA, sobretudo daqueles que integravam o IPLAN, figurando, entre outros, engenheiros, advogados, sociólogos e geógrafos, se deve atentar para o fato de que um grande números destes fizeram cursos de pós-graduação stricto sensu e lato sensu em Economia, bem como cursos de Economia aplicada oferecidos por instituições universitárias nacionais e internacionais e multilaterais, o que evidencia que a influência do pensamento econômico no IPEA não pode ser reduzido a uma expressão matemática, representada pelo número de economistas que integravam os quadros da instituição.

18 O INPES, concebido a partir do núcleo de Planejamento Geral, herdou os estudos e experiências macroeconômicas conduzidos na segunda metade dos anos 1960, voltados para subsidiar a elaboração do Programa de Ação Econômica do Governo (PAEG), do Plano Decenal de Desenvolvimento Econômico e Social, do Programa Estratégico de Desenvolvimento (PED) e das Metas e Bases para a Ação do Governo. Recrutou a maior parte dos seus quadros nos Estados do Rio de Janeiro e de São Paulo (ENTREVISTADO 2). Essa realidade estava relacionada ao pequeno recrutamento de técnicos dos ministérios, superintendências de desenvolvimento regional e secretarias de planejamento e fazenda dos governos estaduais, posto que se concentrou em estudos e pesquisas econômicas acadêmicas e aplicadas, e à presença de faculdades e departamentos de Economia de prestígio nesses estados, à exemplo da Pontifícia Universidade Católica do Rio de Janeiro (PUC-RJ) e da Universidade de São Paulo (USP). O INPES foi formado inicialmente por aproximadamente 20 economistas técnicos jovens, com formação acadêmica consistente, alguns com doutoramento realizado no exterior, em especial nas universidades norte-americanas. Conforme Hamilton de Carvalho Tolosa, o INPES desenvolveu “(...) trabalhos mais na linha macroeconômica, agregada, e outros trabalhos em áreas como distribuição de renda, comércio exterior, mercado de trabalho, crescimento, desenvolvimento, questões que normalmente são tratadas com enfoque mais agregado" (D'ARAUJO, DE FARIAS e HIPPOLITO, 2005, p. 154).

19 Segundo Tolosa “(...) o grupo era muito verde, com pouca experiência em pesquisa. Aprenderam fazendo, deram muitas escorregadelas, e hoje são grandes autores, importantes nas suas respectivas áreas: Pedro Malan, Regis Bonelli, Carlos von Doellinger, Edmar Bacha, Claudio de Moura Castro, Wanderly Manso de Almeida, Thompson Almeida Andrade, entre muitos outros" (D'ARAUJO, DE FARIAS e HIPPOLITO, 2005, p. 154).
} 
e pragmáticas do INPES eram buscadas na literatura econômica norte-americana e nos professores da Universidade da Califórnia (Berkeley). Em alguma medida uma consequência da sua estruturação ter ocorrido a partir do núcleo de Planejamento Geral, que havia recebido a assistência de sucessivas missões dessa universidade, com destaque para as lideradas por Benjamin Higgins e por Albert Fishlow. A relação que o núcleo de Planejamento Geral manteve com as missões de Berkeley se desdobrou nas relações que o INPES manteve com esta e com outras universidades norte-americanas, no final dos anos 1960 e nos anos $1970 .{ }^{20}$

Hamilton Tolosa $(1989$, p. 7) salientou que a condição e função institucional de órgão de pesquisa acadêmica do INPES, acarretaram resistências dentro e fora do Governo Federal, inclusive no próprio IPEA. Embora não tenha explicitado, pode-se deduzir que ocorreram manifestações de resistências entre os técnicos vinculados ao IPLAN, que assumiam funções mais executivas de planejamento e coordenação e que possuíam à época uma formação acadêmica menos consistente. Estas resistências, por sua vez, concorreram para a consolidação, segundo Hamilton Tolosa - discorrendo, no final dos anos 1980, sobre o INPES -, de um "sentido de equipe e uma identidade própria responsáveis pela sua sobrevivência até os dias de hoje" (TOLOSA, 1989, p. 7).

Os vínculos do IPEA com o meio universitário, que ocorreram principalmente por meio do INPES, foram diversos e intensos: economistas acadêmicos e economistas técnicos do IPEA trabalhavam em universidades, ocorreu o envio sistemático destes economistas para os programas de doutoramento ou de especialização no exterior, era frequente a acolhida de professores universitários estrangeiros e nacionais para assessorar as pesquisas em curso e foi constante o financiamento das atividades da Associação Nacional de Centros de PósGraduação em Economia (ANPEC) pelo IPEA.

O IPEA, por intermédio do INPES, assumiu grande relevância na implementação de política e de programas de financiamento voltados para a pós-graduação em Economia no país. O INPES cedia instalações para o funcionamento do Programa Nacional de Pesquisa Econômica (PNPE) e o superintendente do INPES assumia o cargo de secretário executivo

\footnotetext{
${ }^{20}$ A relação entre INPES e universidades norte-americanas envolveu consultoria, pós-graduação e pesquisa interinstitucional, assegurando a consolidação de uma instituição (do Governo Federal) voltada para o desenvolvimento de pesquisa econômica (para o Governo Federal, ou pesquisa econômica como atividade de governo). Os entrevistados 2 e 3 também salientaram que a influência da Comissão Econômica para a América Latina e o Caribe (CEPAL) no INPES era expressiva. O entrevistado 3 afirmou que "no INPES, nos anos 1970, também a influência keynesiana e estruturalista era grande, com personagens como Hamilton Tolosa à frente. Mudou nos anos 1980 em diante, com maior presença do pensamento monetarista, neoliberal" (Entrevistado 3). Essas referências também eram buscadas dentro do país por meio das obras de Eugênio Gudin, Otávio Gouveia de Bulhões, Mário Henrique Simonsen e Roberto de Oliveira Campos (D'ARAUJO, DE FARIAS e HIPPOLITO, 2005).
} 
desse programa. O PNPE financiou a criação dos programas de pós-graduação em Economia e os encontros da ANPEC. ${ }^{21}$

Dessa forma, o IPEA e a ANPEC assumiram papeis de destaque na formação de economistas nos moldes que Mário Henrique Simonsen propugnava para a elite brasileira, qual seja, capazes de conduzir "o país à racionalidade econômica e administrativa indispensável ao desenvolvimento" (SIMONSEN, 1969, p. 290). O IPEA e a ANPEC também se constituíram em instâncias que desempenhavam o papel de correia de transmissão de concepções, doutrinas, metodologias e técnicas de abordagem econômica norte-americanas no Brasil.

\section{A formação do quadro técnico inicial e relações institucionais}

O IPEA foi composto predominantemente por economistas no seu nascedouro, com alguns engenheiros, advogados e especialistas sociais, raramente graduados nas ciências humanas, selecionados junto aos ministérios e à sociedade de uma forma geral. A seleção do quadro técnico do IPEA consistia de entrevistas, geralmente precedidas de indicações de gestores de órgãos do Poder Executivo Federal, de professores das universidades estrangeiras com quem o IPEA mantinha estreita relações e de técnicos da própria instituição, a partir de avaliação de bom desempenho de alunos em cursos por ela oferecidos. ${ }^{22}$ As bases materiais que asseguravam a atratividade da instituição, em termos profissionais, eram os salários

\footnotetext{
${ }^{21}$ Identificar a relação estabelecida entre o IPEA/INPES e a ANPEC demanda uma breve consideração acerca desta associação. A ANPEC foi criada em 1971, no bojo do processo de regulamentação da pós-graduação e da efetiva criação dos programas de pós-graduação e centros de pesquisa no Brasil. A perspectiva do regime cívicomilitar de alcançar um desenvolvimento tecnológico autônomo, presente nos planos nacionais de desenvolvimento do período e fortemente demandado nos períodos do "milagre econômico" e de vigência do II PND, foi determinante para a legislação da reforma universitária de 1969, que instituiu a exigência de pósgraduação stricto sensu como requisito para a progressão na carreira docente e a oferta de recursos financeiros para a criação dos programas de pós-graduação e de centros de pesquisa, de modo a impulsionar a pósgraduação no país. Neste contexto, emergiram os programas de pós-graduação e centros de pesquisa em economia e, consequentemente, a ANPEC com o objetivo de promover de forma institucionalizada uma articulação entre pesquisadores, centros de ensino e pesquisa e órgãos governamentais.

22 Os cursos oferecidos pelo IPEA eram concebidos e realizados pelo Centro de Treinamento Para Desenvolvimento Econômico (CENDEC). Voltava-se prioritariamente para a formação técnica de servidores públicos, a exemplo daqueles vinculados às instituições e agências ministeriais e às secretarias de planejamento e da fazenda dos governos estaduais.
} 
elevados $^{23}$, a autonomia relativa para a produção intelectual e o incentivo e suporte financeiro para a pós-graduação remunerada no exterior.

Hamilton de Carvalho Tolosa salientou que estava em curso, a partir de meados dos anos 1960, a conformação de um "novo" tipo de servidor público. Segundo Tolosa:

foi a época em que se criou praticamente a primeira geração de public servants profissionais. Aquela mentalidade de servir ao país, e não a este ou àquele governo, fazendo isso com independência e proficiência. São pessoas que, se tivessem ido para a iniciativa privada, teria ganhado muito dinheiro, mas foram para o setor público por opção. (D'ARAUJO, DE FARIAS e HIPPOLITO, 2005, p. 164) 24 $^{24}$

Essa visão acerca da profissionalização do serviço público e essa representação do técnico do IPEA e de outros órgãos e agências estratégicas do Estado como public servants profissionais, guarda coerência com um tipo de perfil de 'servidor público' que ocupava carreiras e funções elevadas no âmbito da burocracia, altamente qualificado, profissionalizado e bem remunerado, distinto do 'funcionário público' situado na base da burocracia, pouco qualificado, submetido a rotinas administrativas e mal remunerado. Essa visão e representação coadunam com a gestão autocrática, que se pretendia eminentemente técnica, e com a configuração de uma elite técnica, dentro de uma cultura institucional fundada na racionalidade econômica e administrativa e no planejamento de médio e longo prazo, que o regime cívico-militar apregoava. ${ }^{25}$

A formação de quadros técnicos em alto nível no IPEA foi um objetivo buscado pelos titulares do Ministério do Planejamento. Havia um empenho de liberação dos técnicos para a realização de cursos de especialização e de pós-graduação em nível de mestrado e de doutorado, sobretudo no exterior.

\footnotetext{
${ }^{23}$ Os salários correspondiam aos salários pagos aos técnicos de elevada qualificação da iniciativa privada, permitido pela condição jurídica de fundação que o IPEA usufruía.

${ }^{24}$ Pode-se chegar também à conclusão da conformação desse "novo" tipo de servidor público por meio do depoimento de Roberto Campos, quando disse: "Eu àquele tempo tinha grandes ingenuidades sobre o poder do Estado, inadequada concepção das limitações do Estado e uma enorme superestimação do tecnocrata. Eu acreditava no funcionário missionário possuído do sentido de missão" (GALINKIN, 1989).

${ }^{25}$ Todavia, deve-se reconhecer que a trajetória dos técnicos do IPEA, sobretudo dos economistas, materializou uma relação profissional distinta em relação à iniciativa privada quando comparado aos economistas técnicos de outros órgãos e agências, a exemplo do BNDES e do Banco Central. Enquanto os técnicos do IPEA, sobretudo aqueles vinculados ao IPLAN, em sua grande maioria, permaneciam por muitos anos na instituição, aposentando-se nela ou mesmo saindo dela para outros órgãos e agências públicas, os técnicos de outros órgãos e agências frequentemente saíam para ocupar cargos elevados nas tecnoburocracias privadas de corporações industriais multinacionais e nacionais e de grandes bancos (ENTREVISTADOS 2 e 3).
} 
A formação desse quadro técnico também demandou a realização de cursos de formação técnica e de pós-graduação, respectivamente oferecidos por instituições multilaterais (Banco Mundial, FMI, BID) ou por agências a elas integradas e por universidades. Eram cursos orientados por objetivos institucionais, tendo em vista o domínio de técnicas econômicas aplicadas, como a elaboração de balanço de pagamento, a condução de política monetária e a elaboração de orçamento monetário.

As universidades norte-americanas exerceram um papel central na formação dos primeiros economistas bolsistas, dentro do programa financiado pela USAID. A maioria dos técnicos do IPEA, sobretudo do INPES, se dirigiu para as Universidades da Califórnia (Berkeley), de Stanford e de Vanderbilt, nos Estados Unidos e, em menor número, para as Universidades de Cambridge e de Kent, na Inglaterra. Poucos técnicos realizaram o doutorado em outros países, ou mesmo no Brasil.

Foram estabelecidas articulações interinstitucionais com a Universidade da Califórnia, de Berkeley, que permitiram o deslocamento de "missões" norte-americanas para o IPEA, compostas por equipes de professores, oferecendo cursos e criando e/ou integrando grupos de estudos e pesquisas. ${ }^{26}$ Estas articulações viabilizaram a contratação de consultores internacionais de renome para integrar ou não as "missões", como Albert Fishlow ${ }^{27}$, Samuel Morley, Joel Bergsman, Benjamin Higgins, entre outros ${ }^{28}$.

João Paulo dos Reis Velloso salientou que "o consultor externo devia ser realmente consultor. Isto é, quem formulava as políticas, quem formulava os planos eram os brasileiros, ainda que eles fossem juniores em relação aos professores estrangeiros" (GALINKIN, 1989). Essa passagem evidencia a preocupação com a formação de uma competência técnica própria à Instituição, de um lado, e que esta competência se apresentasse emancipada em relação aos consultores estrangeiros, de outro. ${ }^{29}$ Portanto, a perspectiva era a de

\footnotetext{
${ }^{26}$ Nas palavras do entrevistado 3: "Sobre a pós-graduação no exterior, quem quis sair para se pós-graduar no exterior, do IPLAN e do INPES, saiu. Mas, no IPLAN, técnicos saíram para diversas universidades, inclusive européias e norte-americanas mais "críticas". No INPES predominou a saída para universidades norteamericanas, em particular as mais tradicionais e conservadoras" (Entrevistado 3).

${ }^{27}$ Albert Fishlow ocupou uma importância singular nesse processo, posto que foi responsável por articulações que asseguraram o doutoramento de um grande número de técnicos do IPEA (ou que vieram a trabalhar nele) nas Universidades da Califórnia e de Stanford, como Pedro Malan, Regis Bonelli, Andréa Calabi, Paolo Zaghen, Paulo Cunha, Ricardo Lima, Paulo Levy (D'ARAUJO, DE FARIAS e HIPPOLITO, 2005).

${ }^{28}$ Com a promulgação do Ato Institucional no 5 , em 1968, algumas articulações interinstitucionais estabelecidas com universidades norte-americanas foram rompidas em protesto à institucionalização da ditadura cívicomilitar no país, a exemplo da Universidade da Califórnia, de Berkeley, com iniciativa direta do professor Albert Fishlow. Mas as relações com o IPEA foram retomadas, inclusive com o professor Albert Fishlow contratado como 'consultor' (D'ARAUJO, DE FARIAS e HIPPOLITO, 2005).

${ }^{29}$ Segundo o entrevistado 5, "a atuação dos estrangeiros foi decisiva e muito forte apenas no início da história institucional do IPEA. Assim que o convênio com Berkeley foi desfeito (acho que em 1970, mais ou menos), o IPEA cresceu e se consolidou sobre suas próprias pernas. Eu desconheço ter havido participação estrangeira mais forte ao longo das décadas de 1980, 1990 e 2000. Nessas décadas ela foi pequena e assessória, jamais ligada à coordenação ou qualquer outra coisa de importância estratégica interna" (Entrevistado 5).
} 
conformação de uma instituição com a capacidade de autorreprodução e de tradução das demandas nacionalmente requeridos pelo Estado brasileiro.

Conforme anteriormente assinalado, as iniciativas voltadas para a formação desse quadro técnico contou com o apoio da USAID que, desde 1961, subsidiava trabalhos de universidades norte-americanas voltados para o planejamento e o desenvolvimento em países que estariam, segundo ela, no início do processo de desenvolvimento. ${ }^{30}$ Era comum a presença de equipes de professores universitários norte-americanos participando de processos de planejamento econômico, por exemplo na América Latina.

A pós-graduação de técnicos do IPEA nas universidades estrangeiras, iniciada na segunda metade dos anos 1960 e aprofundada nos anos 1970, culminaria na ocupação, por parte de muitos destes, de postos estratégicos do aparelho de Estado, sobretudo nos Ministérios da Fazenda e do Planejamento (SEPLAN), a partir da transição do regime cívicomilitar nos anos 1980.

\section{A participação do IPEA nos primeiros planos econômicos}

A instituição, ainda como EPEA, teve grande participação na elaboração da política econômica, entre 1964 e $1967^{31}$. Assumiu destaque na elaboração de programas básicos que subsidiariam a criação do Plano de Ação Econômica do Governo (PAEG 1964-67), ${ }^{2}$ que buscava, formalmente, estabelecer o crescimento econômico com inflação baixa. Também assumiu destaque a condução dos diagnósticos macroeconômicos e setoriais voltados para a

\footnotetext{
${ }^{30}$ Estas equipes proporcionavam conhecimentos e informações sobre estes países, úteis para a construção da imagem dos Estados Unidos como país colaborativo, a geração de informações e conhecimentos políticos e econômicos utilizados pelos órgãos e instâncias de Estado e de governo responsáveis pela elaboração e condução da política externa norte-americana, a orientação de investimentos financeiros e corporativos norteamericanos e a formação de instituições e seus corpos tecnoburocráticos e de uma legião de tecnocratas nos países periféricos dentro das concepções teóricas e metodológicas e da pragmática de planejamento e desenvolvimento econômico estadunidense.

${ }^{31}$ A relação estabelecida entre os núcleos (ou grupos) setoriais IPEA (EPEA) e os grupos de trabalho setoriais dos ministérios, inclusive do Ministério de Planejamento, embora de caráter colaborativo, foi eventualmente marcado por contradições e tensões.

32 O PAEG foi um plano econômico do Governo Castello Branco, que tinha como objetivos reduzir a taxa de inflação e retomar o crescimento econômico. No que tange ao combate à inflação, apoiou-se no aumento de impostos e no financiamento da dívida pública por meio da venda de Obrigações Reajustáveis do Tesouro Nacional (ORTNs), declinando de realizar novas emissões monetárias. A redução inflacionária conseguida foi acompanhada da elevação da carga tributária e da redução dos gastos públicos, desencadeando um processo econômico recessivo. Segundo entrevista de João Paulo dos Reis Velloso, o PAEG, ao conciliar "crescimento" e "estabilidade de preços", teria criado um "desenvolvimentismo soft" no Brasil (VELLOSO, 2007).
} 
elaboração do Plano Decenal de Desenvolvimento Econômico (1967-1976). ${ }^{33}$ Esses diagnósticos eram produzidos em parceria com os grupos de trabalho setoriais do próprio Ministério do Planejamento, cuja existência precedia ao IPEA (EPEA).

O desenvolvimento dos estudos conduzidos pelo IPEA (EPEA), que ficariam conhecidos como 'Diagnósticos da Economia Brasileira', foram fundamentais para a afirmação da instituição no âmbito da tecnoestrutura da área econômica do aparato estatal, bem como foram determinantes para a contratação de economistas técnicos e a estruturação dos temas e grupos de estudos que perduraram durante um longo período na instituição. O texto 'Industrialização brasileira: diagnósticos e perspectivas', que integrava o 'Diagnósticos da Economia Brasileira', ao lado da obra 'Da substituição de importações ao capitalismo financeiro', de Maria da Conceição Tavares, foram dois marcos em termos de diagnósticos e de direcionamento do processo de diversificação da estrutura produtiva industrial. ${ }^{34}$

O Plano Decenal, primeira experiência de planejamento de longo prazo no Brasil, foi abandonado. ${ }^{35}$ Mesmo assim, os estudos que redundaram neste plano foram incorporados na elaboração do Programa Estratégico de Desenvolvimento (PED 1968-70), ${ }^{36}$ que buscava

33 O Plano Decenal foi elaborado, em 1966, tendo à frente Roberto de Oliveira Campos, Ministro do Planejamento. Embora tenha sido abandonado, em 1967, com a ascensão de Antônio Delfim Netto, ministro da Fazenda, e de Hélio Marcos Pena Beltrão, ministro do Planejamento, estabeleceu as principais diretrizes da política de crescimento econômico do governo brasileiro, pelo menos até a primeira crise do petróleo. Partindo de um diagnóstico da economia nacional realizado pelo EPEA, previa que a política de substituição de importações deveria ceder lugar ao incentivo para o crescimento do mercado interno, e a política de combate à inflação deveria ser articulada a uma política fiscal orientada para o 'desenvolvimento', dando fim à recessão econômica. Os investimentos deveriam se voltar para a infraestrutura, indústrias básicas, agricultura, sistema de abastecimento, educação e habitação. Previa, ainda, que a empresa privada nacional deveria ser fortalecida por meio do Estado para atuar em condições de igualdade ao lado do capital estrangeiro, bem como que assumiria gradativamente o papel desempenhado pelo Estado na economia (SANDRONI, 1999).

${ }^{34}$ Conforme Regis Bonelli: "Na época, o Ipea era estruturado de uma forma muito diferente da atual. A divisão era por áreas setoriais ou temáticas, seguindo mais ou menos uma estrutura que foi se formando a partir da fundação do instituto, em setembro de 1964, para fazer os diagnósticos setoriais da economia - aliás, o nome da coleção é Diagnósticos da Economia Brasileira. Esses textos cobriam os setores da economia - agricultura, pecuária, indústria, serviços - e outros temas como educação, habitação, saúde etc. Era uma coleção enorme, o primeiro trabalho realmente de peso do Ipea, e um dos mais importantes. Acho que foi esse trabalho que tornou o Ipea conhecido, lá na sua origem" (D’ARAUJO, DE FARIAS e HIPPOLITO, 2005, p. 70 e 71).

${ }^{35}$ Mário Henrique Simonsen afirmou: “(...) o atual governo cuidou de arquivar sob uma capa de silêncio o Plano Decenal (que de fato era mais quinquenal do que decenal) que the fora legado pelo seu antecessor. $O$ planejamento só se torna efetivamente útil quando se substitui a concepção editorial pela operacional. E para chegar a esta última etapa, dois requisitos se fazem indispensáveis. De um lado, um espírito de continuidade administrativa que conduz o Governo a tomar a sério os seus planos, encarando-os como um compromisso impessoal de execução, e não apenas como livros para publicação. De outro lado, que os planejadores se submetam a objetivos compatíveis, por mais ásperos que estes pareçam, e não tentem esconder a sua inconsistência por meros artifícios aritméticos de apresentação". (SIMONSEN, 1969, p. 194 e 195)

36 O PED foi baseado nas diretrizes que orientaram o Plano Decenal 1967-76. Propunha-se expandir as exportações e o mercado interno e reduzir os custos de produção das empresas privadas nacionais mediante a adoção de uma política monetária com baixas taxas de juros reais. Para tanto, o Estado deveria ampliar os investimentos em infraestrutura e em ciência e tecnologia, sem expansão da carga tributária e limitando a 
conduzir o crescimento com a inflação o mais reduzida possível. ${ }^{37} \mathrm{O}$ abandono do Plano Decenal em favor do PED revela contradições no âmbito da elite político-administrativa quanto à orientação econômica do país. De fato, contrapunha elites políticas e econômicas quanto à extensão e amplitude do planejamento de longo prazo, a exemplo de Roberto Campos e de Antônio Delfim Netto. ${ }^{38}$

Os estudos macroeconômicos do PED realizados por Albert Fishlow, voltados para a questão da inflação, demonstrou ser possível crescer economicamente e conter a inflação, em uma clara contraposição às posições do FMI, segundo o qual a condução de uma política de controle da inflação devia preceder uma política voltada para o crescimento. A participação dos economistas técnicos do Ministério da Fazenda na concepção do PED foi especialmente intensa e importante na elaboração do documento que proporcionaria as diretrizes econômicas do plano. ${ }^{39}$

dívida pública. No âmbito do PED previa-se a realização das reformas administrativa e educacional, tendo em vista a modernização do Estado. O PED desencadeou o chamado "Milagre Econômico" brasileiro (D'ARAUJO, DE FARIAS e HIPPOLITO, 2005).

${ }^{37}$ Um dos estudos realizados e que contribuiu para a deflagração do PED foi a pedido de Antônio Delfim Netto, Ministro da Fazenda, que consistia no diagnóstico e apresentação de diretriz para o setor industrial. Este estudo envolveu técnicos do IPEA e do Ministério da Fazenda. Pelo IPEA participaram Pedro Malan, Régis Bonelli e Albert Fishlow, e pelo Ministério da Fazenda Afonso Celso Pastore, Carlos Antônio Rocca, Carlos Eduardo Carvalho, Paulo lokota, Akihiro Ikeda e Paulo Cipollari. Dentre as recomendações do documento final destaca-se a possibilidade de expandir a oferta de crédito e de flexibilizar a política monetária, posto que a retomada da atividade econômica, à medida que ocorreria inicialmente por meio da ocupação da capacidade ociosa existente, não acarretaria, em curto prazo, pressão inflacionária (D'ARAUJO, DE FARIAS e HIPPOLITO, 2005).

${ }^{38}$ Essa contraposição pode ser confirmada por meio da seguinte passagem de entrevista concedida por Pedro Sampaio Malan: "Em fins de 1966 e início de 1967, estávamos começando a trabalhar em planos decenais, olhando a economia brasileira 10 anos à frente, algo que o ministro Roberto Campos, com razão, estimulava muito. Quando Delfim Netto assumiu o Ministério da Fazenda, em março de 1967, Afonso Celso Pastore, Eduardo Carvalho, Carlos Antônio Rocca vieram de são Paulo para o Rio e ficaram algum tempo no Ipea trabalhando conosco. (...) $O$ trabalho com planos decenais foi substituído pela elaboração de um programa estratégico de desenvolvimento para o triênio 1968/70. (...) só foi retomada em outros termos (e em condições nacionais e internacionais radicalmente distintas) pelo ministro Reis Velloso em 1974, quando assumiu o Ministério do Planejamento no Governo Geisel". (D'ARAUJO, DE FARIAS e HIPPOLITO, 2005, p. 61)

${ }^{39}$ Nas palavras do ex-ministro do Planejamento Hélio Beltrão: "Então houve um diagnóstico que foi feito inicialmente no IPEA e depois um trabalho em conjunto com os técnicos do Ministério da Fazenda, e diagnosticamos que a inflação era naquele momento, a inflação recente, era predominantemente de custos e que era preciso criar incentivos para a demanda para promover o revigoramento imediato da economia e tirar o país daquela situação. Foi um trabalho importante que se fez e esse diagnóstico foi um diagnóstico muito importante. Ao mesmo tempo criamos incentivos à demanda e provocamos uma política de redução de custos e de insumos básicos e isso acabou dando certo" (GALINKIN, 1989). Essa passagem do ex-ministro do Planejamento Hélio Beltrão evidenciou a participação do IPEA na preparação do PED, com realce para o diagnóstico da forma predominante em que se manifestava a inflação - "inflação de custo" -, o que permitiu a adoção de ações de retomada do crescimento econômico, a exemplo de incentivos à demanda, sem que esse crescimento redundasse em aceleração da inflação e em desequilíbrio fiscal, permitindo convergir as propaladas 'responsabilidade fiscal' e controle da inflação, caro aos monetaristas, e a aceleração do crescimento econômico e industrial, caro aos desenvolvimentistas. Essa passagem também evidenciou a interação entre os economistas técnicos do IPEA e os grupos setoriais do Ministério do Planejamento, sob a gestão do ministro Hélio Beltrão, de um lado, e os economistas técnicos do Ministério da Fazenda, sob gestão 
O Ministério do Planejamento procurou assegurar respaldo político ao PED junto às elites políticas por meio de debates e incorporação de proposições. Assim teve curso o envolvimento técnico-científico e político de economistas técnicos do IPEA junto aos economistas técnicos do Ministério da Fazenda e a membros do Poder Legislativo durante os processos, respectivamente, de concepção e elaboração do PED e da sua apreciação e aprovação. ${ }^{40}$

A dimensão desse envolvimento concorreu para a sedimentação de certas características às representações institucionais do IPEA e aos papéis sociais desempenhados por seus técnicos em torno da função e importância social dos mesmos, como a superestimação da importância da instituição e dos seus técnicos na construção do país e das instituições e políticas de Estado, a postura acrítica quanto ao conteúdo tecnocrático e autoritário das relações estabelecidas entre Estado e sociedade, a compreensão do "subdesenvolvimento" como etapa em processo de superação no país e a atuação do economista técnico do IPEA como um "funcionário missionário possuído do sentido de missão". ${ }^{41}$

Em resumo, o PED partiu de uma estratégia de desenvolvimento que deveria contemplar uma fase de aceleração do crescimento (ou de transição) e uma fase de trajetória de equilíbrio dinâmico de longo prazo (ou alto crescimento) (VELLOSO, 2007, p. 194 e 195). Com base nesta estratégia indicou a necessidade de expandir as exportações e o mercado interno e de reduzir os custos de produção das empresas privadas nacionais, com a adoção de uma política monetária apoiada em taxa de juros reais baixas. O PED acentuou a necessidade da ampliação do investimento público em infraestrutura econômica (energia elétrica, petróleo, transportes e comunicações) por meio da expansão das empresas estatais.

do ministro Antônio Delfim Netto, de outro, na concepção do $P E D^{39}$. Tão importante quanto a convergência entre os Ministérios da Fazenda e do Planejamento foi a participação do IPEA em atividades de coordenação econômica do Governo Federal.

${ }^{40}$ Segundo Kandal: "Nesse ano de 68, eu me lembro de duas coisas que marcaram muito a minha memória. Uma foi um trabalho coletivo feito entre a Fazenda e o IPEA. Pelo IPEA participavam o Fishlow que tinha voltado chefiando a segunda missão (...), eu, Malan, Bonelli e Marcelo Paiva. E pela Fazenda era Pastori, Rocca, Ykeda e Cipollari. Nós tivemos um mês para preparar um documento de diretrizes econômicas. E o Delfim, tinha chegado com aquela sede de poder que o caracteriza (...). Esse documento foi um documento muito simples até pela exigüidade do tempo. Eu ainda tenho um exemplar desse documento, é um documento muito pouco conhecido. Isso foi a inflexão da política econômica (...), foi o início do Milagre. Esse documento é a reversão da estagnação, ou do ajustamento no 6.466 Roberto Campos/Bulhões, e entra na fase pré-Milagre. (...) Eu tive muito pouca confiança nas conclusões de um estudo tão temerário, mas o fato é que ele saiu melhor do que a encomenda" (GALINKIN, 1989).

${ }^{41}$ Maria da Conceição Tavares identificou estas características nos papéis sociais desempenhados pelos economistas técnicos do IPEA nos anos 1960 e 1970, quando disse: "Meteu-se na cabeça de uns meninos progressistas adoradores de um autoritário que eles tinham poder, que eles iam fazer o Brasil, isso é que é o mau, e eu bem que avisei, não vai fazer Brasil nenhum, não é assim. Mas a malta acreditava. Muitos foram meus alunos, partiram das minhas ideias progressistas, mas nunca das minhas ideias realistas, eu jamais disse que um corpo de técnicos faz o Brasil. Há mais de 10 anos tenho dito isso, e entra por aqui e sai por aqui" (GALINKIN, 1989). 
Tinha em vista a transformação destas empresas em conglomerados, e era orientado por uma política fiscal baseada, sobretudo, na capacidade já existente, sendo vedado o aumento da carga tributária e limitada a expansão da dívida pública. Também foi realçado o crescimento agrícola pela via da modernização, incorporando a mecanização e a quimificação nas atividades agropecuárias. O PED destacou, por fim, o desenvolvimento científico e tecnológico, em grande medida uma consequência da colaboração entre o IPEA e a Financiadora de Estudos e Projetos (FINEP) no processo de elaboração do Programa.

É possível afirmar que o envolvimento destacado do IPEA com a concepção e implementação do PED ocupou grande importância na legitimação da instituição recémcriada na estrutura administrativa do Estado, na ampliação de seus quadros técnicos e instalações, na complexificação da sua estrutura institucional e na edificação dos fundamentos da sua identidade institucional.

\section{Considerações finais}

O IPEA foi concebido e efetivamente criado a meio caminho do processo de consolidação das mudanças no bloco histórico, em curso, entre o Plano de Metas e a institucionalização do regime cívico-militar. As atribuições de coordenação das ações de planejamento estratégico de Estado, de formulação de políticas econômicas e sociais e de criação de instituições públicas demandadas pela expansão do sistema do capital no Brasil, direcionadas ao IPEA, o converteram em uma das instituições-chave do processo de expansão dos interesses hegemônicos no bloco no poder que haviam direcionado as mudanças em curso no bloco histórico.

Concebido e criado como parte integrante da construção da estrutura administrativa do Estado, por intelectuais orgânicos de funções amplas, vinculados ao mundo do capital e integrantes da alta cúpula do regime cívico-militar, tinha como objetivo central concorrer para a viabilização de processos de tomada de decisões com eficiência e eficácia no que tange ao planejamento econômico. Na sua fase de estruturação, em curso entre 1964 e 1970, foi se qualificando como um dos instrumentos estratégicos para o exercício do autocratismo burguês no Brasil, sob regime cívico-militar.

REFERÊNCIAS BIBLIOGRÁFICAS

BARBOSA, Walmir. Ipea (Instituto de Pesquisa Econômica Aplicada): planejamento e reprodução do capital (1964-2004). Tese (Doutorado) - Universidade Federal de Goiás, Faculdade de História, 2012. 
BRASIL. Ministério do Planejamento. Escritório de Pesquisa Econômica Aplicada (EPEA). Portaria no 81 (10-91964). DO de 17-9-1964.

Instituto de Pesquisa Econômico-Social Aplicada (IPEA). Decreto-Lei 200 (25-02-1967).

CARVALHO, W. A. Fundação do IPEA: formação, desenvolvimento e impasses. IPEA: Brasilia/Rio de Janeiro, 1996.

D’ARAUJO, Maria Celina, DE FARIAS, Ignez Cordeiro e HIPPOLITO, Lúcia (Orgs). IPEA - 40 Anos: uma trajetória voltada para o desenvolvimento. Depoimentos ao CPDOC. Rio de Janeiro: CPDOC/FGV, 2005.

DURAND, Maria Rita G. Loureiro. Formação das elites político-administrativas no Brasil: as instituições de pesquisa econômica aplicada. Revista do Serviço Público/Fundação Escola Nacional de Administração Pública v.1, n.1 (nov. 1937) - Ano 48, n.1 (jan-abr/1997). Brasília: ENAP, 1997.

ENTREVISTA 1, 2, 3, 4 e 5. Entrevistas conduzidas a técnicos do IPEA. Brasília, 2011.

GALINKIN, Maurício. Comemoração dos 25 anos do IPEA. Depoimentos acerca da trajetóriado IPEA. Brasília: Instituto de Pesquisa Econômica Aplicada/Centro de Treinamento para o Desenvolvimento Econômico e Social, 1989. 30 minutos. VHS.

LOUREIRO, Maria Rita. Economistas e Elites Dirigentes no Brasil. Revista Brasileira de Ciências Sociais, Rio de Janeiro, 7(20): 47-65, out., 1992.

SANDRONI, Paulo. Novíssimo Dicionário de Economia. São Paulo: Editora Best Seller, 1999.

SIMONSEN, Mario Henrique. Brasil 2001. Rio de Janeiro: Editora APEC, 1969.

VELLOSO, João Paulo dos Reis. IPEA - Uma Instituição para Pensar o Brasil. In: COÊLHO, Francisco da Silva, SZMRECSÁNYI, Tamás (Orgs). Ensaios de História do Pensamento Econômico no Brasil. São Paulo: Athas, 2007.

VERSIANI, Flávio Rabelo. Intercâmbio, Verbas e Pluralismo: a ANPEC na Evolução do Ensino e da Pesquisa em Econômica no Brasil. In: COÊLHO, Francisco da Silva, SZMRECSÁNYI, Tamás (Orgs). Ensaios de História do Pensamento Econômico no Brasil. São Paulo: Athas, 2007.

TAVARES, Maria da Conceição. Da substituição de importações ao capitalismo financeiro. Rio de Janeiro: Zahar, 1972.

TOLOSA, Hamilton Carvalho. O Papel da Pesquisa Econômica nos Vinte e Cinco Anos do IPEA. In: IPEA. A memória da produção do IPEA (edição comemorativa dos seus 25 anos). Rio de Janeiro: IPEA/INPES, 1989. 